\title{
Collaborative risk-driven intervention: research supporting technology-enabled opportunities for upstream virtual services in rural and remote communities
}

\author{
Chad Nilson*
}

\begin{abstract}
In 2011, Canada's Hub Model of Collaborative Risk-Driven Intervention was launched in Prince Albert, SK. Since that time, over 60 communities across the country have replicated the initiative, resulting in over 9,500 rapid interventions of acutely-elevated risk. For the most part, however, these multi-sector efforts to detect elevations in risk, share limited information, and mitigate risk before harm occurs, have taken place in small-to-large-size communities. Still uncertain, is how the benefits of the Hub Model can be expanded to support individuals in rural and remote communities. This article represents a compilation of extracts from a larger body of work conducted to research, explore, and propose a pilot project for application of collaborative risk-driven intervention in a virtual environment. Part of this effort includes a review of literature on the Hub Model, adaptations of human service initiatives, and the relationship between human service provision and information and communication technology (ICT). Consultations with 199 different human service and ICT professionals lay the groundwork for development of theory, assumptions, risks, options, and solutions for implementation of a tech-enabled Hub. Of course, the implications for service mobilization through a remote presence extend far beyond just the Hub Model. Therefore, this article aims to encourage and inspire action-based research that propels a wide variety of tech-enabled opportunities for improving community safety and well-being.
\end{abstract}

Key Words Hub; technology; risk; innovation; collaborative risk-driven intervention; human service.

Journal of CSWB. 2017 Dec;2(3):76-86 www.journalcswb.ca

\section{INTRODUCTION}

In 2011, the journey for what has now become known as "Canada's Hub Model" started in Prince Albert, Saskatchewan. In response to a measurable need to mitigate acutely elevated risk before harm occurs, human service providers embarked upon a new process of risk detection, information sharing, and rapid multi-sector intervention (Nilson, 2014). Since that time, the Hub Model of collaborative risk-driven intervention has been replicated in over 60 communities across the country (Global Network for Community Safety, 2016). Although the model has been applied in some smaller urban (Gray, 2016) and First Nation (Nilson, 2016a) communities, there remain significant resource and geographic barriers to its expansion into rural and remote communities.

To overcome these barriers, Community Safety Knowledge Alliance requested the University of Saskatchewan's Centre for Forensic Behavioural Science and Justice Studies to lead the development of a research-based pilot project plan that would set the stage for the Hub Model to be tested in a virtual environment. The preparations for that pilot project plan uncovered several important and valuable findings from both a research and practitioner perspective. To further disseminate these findings, this article extracts key components of the larger document aimed to guide implementation of a tech-enabled Hub in Saskatchewan (and/or other provinces). Its purpose is to present original research, while also exploring the art of the possible concerning virtual applications of human service delivery in rural and remote communities where human services are limited or non-existent. While the focus of this article may be on TechEnabled Hubs, the utility and reach of findings presented herein extend well beyond the field of collaborative riskdriven intervention. 


\section{LITERATURE REVIEW}

The project's literature review focused on identifying key themes and lessons learned in three major areas: collaborative risk-driven intervention, adaptations of other human service models in remote communities, and applications of information and communication technology in the human services. Due to the diverse nature of these three topics, several search strategies were employed. These include direct communication with Hub evaluation authors, web-based searches, requests to government, published literature searches, and reference-based snowballing.

In reviewing the respective literatures on all three topics, thematic analysis was conducted to highlight major themes and widespread agreement in evidence-based practices concerning the Hub Model, human service adaptations, and information and communication technology. Key words used to search for relevant literature included collaboration, risk-driven intervention, human service adaptations, information and communication technology, remote presence technology, and virtual human service delivery. Key databases for literature included JSTOR, EBSCOhost, Google Scholar, and Academic Search Complete. The following sub-sections summarize main lessons from those literature bodies.

\section{Collaborative Risk-Driven Intervention}

Collaborative risk-driven intervention is the process of riskdetection, which leads to disciplined and limited information sharing, and that is followed by a mobilization of multiple human service providers to intervene and mitigate risk before harm occurs (Nilson, 2016a). The core manifestation of this process in Canada is the Hub Model. In short, the $\mathrm{Hub}$ is "an evidence-based collaborative problem-solving approach that draws on the combined expertise of relevant community agencies to address complex human and social problems before they become policing problems" (McFee \& Taylor, 2014 p. 2). As the first evaluation of the Hub Model in Canada describes:

The Hub is structured as a venue for human service professionals from a variety of human service disciplines, to meet and collaborate on interventionist opportunities of addressing situations of acutely-elevated risk. The Hub itself is inherently risk-driven, and lends itself to both secondary and tertiary efforts of prevention. The Hub meets Tuesday and Thursday mornings for up to 90 minutes each day. The focus of these meetings is to identify complex risks of individuals or families that cannot be addressed by a single agency alone. When situations are brought to the table by one of the partner agencies, the appropriate human service professionals become engaged in a discussion, which results in a collaborative intervention to connect services and offer supports where they were not in place before. The goal of the Hub is to connect individuals-in-need to services within 24 to 48 hours. (Nilson, 2014 p.9)

The Hub was designed to be a venue for risk detection, limited information sharing, and collaborative intervention planning. It is not an entity or an organization, but simply a forum for multi-sector collaboration (Nilson, 2014). The Hub was not created to coordinate case management nor provide intensive follow-up to families in need. These are the responsibilities of agencies after a Hub discussion (Russell \& Taylor, 2014). Instead, the Hub Model brings human service providers together in a very efficient, disciplined discussion process to simply identify client risk factors, determine the best possible supports for the client, and plan an intervention that offers these supports. Once an intervention is deployed, the relevant human service agencies involved in the discussion take over outside of Hub (McFee \& Taylor, 2014).

Since 2012, a number of evaluations have been completed on the Hub Model. The very first evaluation of the Hub Model was Nilson's (2014) Preliminary Impact Assessment of the Prince Albert Hub. The main findings of that report indicate that the Hub was effective at breaking down long-standing institutional silos and gaining clients quicker access to services. As the model started to be applied in Ontario, evaluations were conducted in Toronto (Ng \& Nerad, 2015), Brantford (Babayan, Landry-Thompson, \& Stevens, 2015), Kitchener (Brown \& Newberry, 2015), Guelph (Litchmore, 2014), Ottawa (Lansdowne Consulting, 2016), Barrie (Nilson, 2017), Chatham-Kent (Nilson, 2016b), and Cambridge (Brown \& Newberry, 2015; Newberry \& Brown, 2017), to name a few. Outside of Ontario, Public Safety Canada sponsored an evaluation of Canada's first on-reserve application of the model in Maskwacis, Alberta (Nilson, 2016a).

Some of the initial findings reported in the evaluation literature include increased service access (Nilson, 2014; Nilson, 2017); clearer determination of client needs (Babayan et al., 2015); improved communication among agencies ( $\mathrm{Ng} \&$ Nerad, 2015); reduced barriers to support (Brown \& Newberry, 2015; Nilson, 2017); improved client-service provider relations (Nilson, 2016a); and increased efficiencies in human service delivery (Lansdowne Consulting, 2016). In addition to these findings, other evaluations describe the model's application in large urban areas ( $\mathrm{Ng} \&$ Nerad, 2015), small urban areas (Babayan et al., 2015), and rural on-reserve communities (Nilson, 2016a).

\section{Adaptations of Other Human Service Models in Rural and Remote Communities}

To learn from the adaptations of other human service models in rural and remote communities, five short case reviews were conducted in the areas of mental health crisis intervention (Skubby, Gonfine, Novisky et al., 2013); family violence programming (KYRHA, 2015); homelessness and housing (Waegemakers-Schiff \& Turner, 2014); home visiting (Del Grosso et al., 2014); and healthy learning (Naylor, McKay, Scott et al., 2009). A case study approach was elected to highlight the practical implications of service model adaptation. Following a careful review of the human service literature, each case study was chosen for its ability to demonstrate how existing human service models have been adapted to fit rural and remote environments. Central to the case study process was identifying different lessons to consider in moving forward with adaptation of the Hub Model in rural and remote communities. While some of these lessons may be more applicable to tech-enabled Hubs than others, they all have significant value for the planning process required to 
implement a remote presence initiative. The following lessons were gleaned from the above case studies:

1) Be prepared to adjust expectations and roles.

2) Strive for equal ownership and a shared value of the initiative among community partners.

3) Allow for more time in the preparation stage than in other less remote environments.

4) Be willing to adjust training and logistical needs to meet service provider capacity and need.

5) Look within the community to find and mobilize what resources are available (as opposed to focusing on resources that are not available).

6) Consider a regional perspective for expanding service access and resource availability.

7) Implement video communication technology to overcome limitations in service access or quality.

8) Incorporate culture and tradition into delivery of the model.

9) Be prepared for variation in the adaptation practices across rural and remote communities.

10) Keep the model simple and easy to implement.

11) Make sure ongoing support is accessible and responsive to community needs.

12) Allow for cultural infusion, which will foster community ownership, stakeholder buy-in, and target group engagement.

\section{Information and Communication Technology}

One of the challenges with understanding ICT is that defining the term Information and Communication Technology becomes tedious in light of the diverse applications of the term within several different contexts and treatments. Some experts (Rouse, 2005) define ICT as an umbrella term that includes any variety of communication devices such as radio, cellular phones, computers, and video conferencing. Others (TechTerms, 2010) explain ICT as a term that refers to technologies that provide access to information through telecommunications in real time, such as instant messaging, voice-over-Internet, video conferencing or social media.

Several observers see ICT as a useful tool for education (Trucano, 2005), economic growth (Avgerou, 2003), and social development (Kozma, 2005). In fact, some researchers (Caperna, 2010) argue that ICT is not simply a tool, but a crucial aspect of sustainable policy that is capable of mitigating various community challenges such as literacy, community involvement in planning, geography, and service access.

Even when discussing applications of ICT, there are differences between use in the business (Akomea-Bonsu, 2012), tourism (Dimitrios \& O'Connor, 2005), education (Pelgrum, 2001), adult learning (Selwin, Gorad, \& Furlong, 2006), community planning (Silva, 2010), social (Wang, Carley, Zeng et al., 2007), and even technology (Cohen, Garibaldi, \& Scarpetta, 2004) sectors. Overall, this variation in context and application makes defining ICT a difficult endeavour.

To ease this burden, Zuppo (2012) presents a framework for hierarchical classifications of ICT definitions and terms. Her purpose was to not only highlight the truly multidisciplinary nature of ICT, but also to streamline global definitions and applications of the term to help foster more precise keyword searches, resulting in more efficient and effective gathering of information relating to ICT. Relevant to the current research, two of Zuppo's lower level classifications illustrate the difference between ICT infrastructure and ICT devices. Whereas the former refers to connectivity, access, and signal availability, the latter refers to whether users of technology possess devices such as phones, computers, or tablets.

Considering all of this, for the purposes of this article, ICT refers to a technology with diverse applications that-via appropriate infrastructure and device(s)—enables real-time communication between two or more recipients through text, voice and/or video signal.

\section{CONSULTATION PROCESS}

To develop a well-informed pilot project, key stakeholders from policing, education, justice, victim services, mental health, addictions, social welfare, child protection, probation, culture, leadership, community outreach, housing, family services, and child protection were consulted in the process $(\mathrm{N}=199)$. Participants to the consultation process represent four different groups: Hub practitioners $(n=97)$, non-Hub human service professionals $(n=65)$, model adapters $(n=16)$, and information and communication technology experts $(n=21)$.

Engagement of consultation participants involved a combination of different recruitment strategies. Hub practitioners were selected based upon several factors related to service area, jurisdiction, involvement of technology, and level of rurality. Hub practitioners from Ontario and Saskatchewan, as well as those representing on-reserve and off-reserve Hub tables, were engaged in the process. Non-Hub practitioners were selected based upon either their delivery of service to rural/remote communities and/or their involvement in multi-sector collaboration while also not having any experience with the Hub Model. Model adopters were identified through a review of literature on applications of pre-existing models in rural/remote communities. Finally, information and communication technology experts were identified through suggestions within the ICT community.

Dialogue from these four cohorts was captured in a few different ways. A majority of participants $(n=119)$ were engaged through face-to-face interviews in a group or individual setting. Others were consulted via telephone $(\mathrm{n}=47)$. A small minority $(\mathrm{n}=12)$ participated through an email exchange. Lastly, in the spirit of information and communication technology, group interviews with members of two separate Hubs $(n=21)$ were conducted through video conference. ${ }^{1}$

Each stakeholder group was asked a series of different questions. Hub practitioners were asked questions pertaining to adaptation of the Hub Model, requirements for collaborative risk-driven intervention to occur in a technological environment, and potential challenges and barriers to such an approach. Human service professionals not currently involved in Hub were asked to discuss their reaction to providing services to clients in a multi-sector technological

\footnotetext{
The Weyburn/Estevan/Carlyle Hub in Saskatchewan and Durham Connect in Ontario each meet weekly through video conference. The author was able to facilitate the consultation process remotely from Prince Albert, SK.
} 
environment. Model adapters were asked to share their experience and knowledge of adaptations of existing human service models in rural, remote, or technological communities. Finally, ICT experts were asked questions about current ICT capacity, potential capacity, and key factors to consider in enabling human service collaboration and service provision through a technological environment.

To analyze data from the consultation process, responses were first organized into similar groupings under the same question. From these various groupings, feedback was then examined using thematic analysis. During this process, several key themes repeatedly appeared in the dialogue of each respondent cohort. Analysis of respondent dialogue revealed multiple mentions of adaptability, key ingredients, potential barriers, technology considerations, appropriate ICT formats, and tech-enabled Hub discussant qualities. In addition to these themes, three main concerns were also highlighted by several consultation respondents.

First, many of the Hub practitioners were initially resistant to the idea of a tech-enabled Hub, simply because it lacks conventional face-to-face human interaction. However, when confronted with the reality that some communities literally have no services, many respondents were quick to realize the utility of a tech-enabled Hub. In the end, there grew considerable enthusiasm and support for the concept of a tech-enabled Hub among consultation respondents.

Another major concern during the consultation process was the fact that not only are rural and remote communities lacking resources for a proper onsite intervention, but they also have no services for ongoing support post-intervention. As a result, a lot of dialogue during the consultation process focused on the actual day-to-day service provision to clients engaged through a tech-enabled Hub. Overall, many of the consultation respondents were favourable to exploring ways in which they could provide services to rural and remote clients in an ongoing tech-enabled capacity.

A third major concern among consultation respondents was the resource makeup of a so-called tech-enabled Hub. Assumingly regional and/or provincial in nature, there were numerous questions around who would make up the techenabled Hub and, more significantly, who would fund it. This sparked conversation around a number of different options, designs, locations, and governance structures. Ultimately, several consultation respondents favoured a purely techenabled Hub with discussants located in different parts of the region (or province). This allows for more physical coverage of at least one team member, to be accompanied by a local human service provider (e.g., referring agent), and the rest of the tech-enabled intervention team.

Overall, there was a variety of suggestions and ideas provided during the consultation process. These suggestions provide a lot of new questions to consider in planning a pilot project or pursuing related research. In aggregate form, feedback from respondents in the Hub discussant, human service provider, model adopter, and ICT expert consultation cohorts is summarized within Table I.

\section{PROPOSING A PILOT PROJECT}

The literature review and consultation process were instrumental in the design of a proposed pilot project for implementing collaborative risk-driven intervention in a virtual environment. In an effort to fulfill the main goals of this project, the following subsections present different components of the overall pilot project plan.

\section{Theory of Change}

The purpose of the Hub Model, including a tech-enabled application, is to contribute towards community safety and well-being. To achieve this, a number of key activities are undertaken to better inform and engage appropriate human service providers-thereby improving human services and reducing risk.

To conceptually map this process, a logic model is illustrated in Figure 1. The theory of change for a tech-enabled Hub suggests that risk detection by local assets (e.g., RCMP, community health worker) triggers a referral to the so-called tech-enabled Hub. This team then begins the tech-enabled discussion process, where they share limited information and begin planning a tech-based intervention. During the intervention (and with the help of a local technology access coordinator), services become mobilized, which triggers integrated service delivery from relevant human service professionals. As a result of these activities, there occurs an increase in multi-agency awareness of risk factors and client needs become addressed. The resulting human service improvement and risk reduction contributes towards improved community safety and well-being.

\section{Risks to Consider}

Throughout the implementation of such a project, there are a number of risks that the implementation team should be aware of. Having a plan to overcome these risks will be critical to the success of the pilot project. The risks shown in Table II have been identified through research on collaboration-based human service models, a review of adaptations of other models, and consultations with key stakeholders. This list is not comprehensive and should only be used as a starting point to provide some idea of potential risks to consider in the implementation process. Furthermore, the strategies to overcome these risks are also limited and should be expanded.

\section{Key Assumptions}

Moving forward with a tech-enabled Hub requires a few key assumptions to be met. Making sure these assumptions are true will improve the probability of success for the implementation of a tech-enabled Hub. Where any of these assumptions are not true, the implementation team must work together to identify a solution.

There is a group of motivated and experienced human service professionals who are interested and available to be part of this project.

- There is support from various levels of government (e.g., local, provincial, Aboriginal, federal).

- There are rural and remote communities with limited to no access to human service delivery.

- As a collective, the membership organizations will work together to secure appropriate technology access.

- Accessible, user-friendly, and reliable technology is available to all project partners. 
Local human service professionals will identify risk and make referrals to the virtual Hub.

- There is a source or provider of mobile technology made available to clients.

- There are locally-based coordinators of technology access and onsite support to clients.

- There is a set review period that will allow for reflection, trouble-shooting, and improvement.

\section{Team Configuration Options}

Throughout the consultation process, a number of different team configurations emerged. For the most part, there was usually consistency in the delivery of service post-intervention. That almost always involved a human service provider continuing the client-care provider relationship using an ICT solution. Where differences emerged was in the actual structure, resourcing, and location of the Hub team itself. As

TABLE I

A summary of feedback from the consultation process-organized by theme

\begin{tabular}{|c|c|}
\hline Theme & Feedback from Consultation Respondents \\
\hline Adaptability & $\begin{array}{l}\text { - The risk detection process will require additional community outreach/support } \\
\text { - Resourcing of the Hub with full time positions will be required } \\
\text { - The discussion process (and Four Filters) will remain the same } \\
\text { - The intervention will have to be supported by onsite and remote presence discussants } \\
\text { - Collaboration and integrated supports will have to continue after the intervention } \\
\text { - Service providers involved in the intervention should also provide the ongoing services } \\
\text { - The tech Hub should be structured to meet regional/provincial needs (not just local) }\end{array}$ \\
\hline Key Ingredients & $\begin{array}{l}\text { - Clear cost-effectiveness } \\
\text { - Local champions } \\
\text { - Effective communication } \\
\text { - Fidelity to the original Hub Model (i.e., Four Filters) } \\
\text { - Supportive and flexible coordination } \\
\text { - Community ownership } \\
\text { - Protocol and structure within a technological environment } \\
\text { - Dedicated positions for Hub discussants } \\
\text { - Proper skillset in intervention and comfort with technology } \\
\text { - Roll out of pilot must be slow-paced and supported } \\
\text { - Security and confidence with the technology } \\
\text { - Mechanism of self-referral and/or community referral } \\
\text { - Someone onsite to provide ICT access to clients } \\
\text { - Guaranteed access to human service supports }\end{array}$ \\
\hline Potential Barriers & $\begin{array}{l}\text { - Limited risk detectors in rural/remote communities } \\
\text { - Staff/leadership turnover } \\
\text { - Limited anonymity/confidentiality in rural/remote communities } \\
\text { - Attention drift to other priorities } \\
\text { - Historical distrust for government agencies } \\
\text { - Loss of face-to-face client interaction } \\
\text { - Limited skills/knowledge/comfort with ICT } \\
\text { - Limited access to reliable technology } \\
\text { - Long institutional legacies of face-to-face service provision } \\
\text { - Loss of cultural/community familiarity with regional/provincial approach }\end{array}$ \\
\hline Technology Considerations & $\begin{array}{l}\text { - Technological connectivity, access, strength, reliability, capacity, acceptance, affordability } \\
\text { - Local bandwidth, data coverage, network access } \\
\text { - Single provider of ICT solutions } \\
\text { - Local knowledge on operating ICT solutions } \\
\text { - Support for clients in using the ICT } \\
\text { - Video-based solutions are preferred over text or voice-based solutions } \\
\text { - Mobile video devices are critical for the intervention } \\
\text { - Stationary video solutions could be used for discussion process and ongoing support }\end{array}$ \\
\hline Appropriate Technology Formats & $\begin{array}{l}\text { - Stationary video-solution (discussion process) } \\
\text { - Mobile video-solution (interventions and ongoing service provision) } \\
\text { - } 4 \mathrm{G} / \mathrm{LTE} \text { wireless, satellite signal, fiber optics }\end{array}$ \\
\hline Tech-Enabled Hub Discussant Qualities & $\begin{array}{l}\text { - Must be experienced human service professionals } \\
\text { - Must be adaptive, flexible, and innovative in their solutions } \\
\text { - Must have some level of decision-making authority } \\
\text { - Comfortable in a technological environment } \\
\text { - Committed to position for longer period of time (low turnover) }\end{array}$ \\
\hline
\end{tabular}




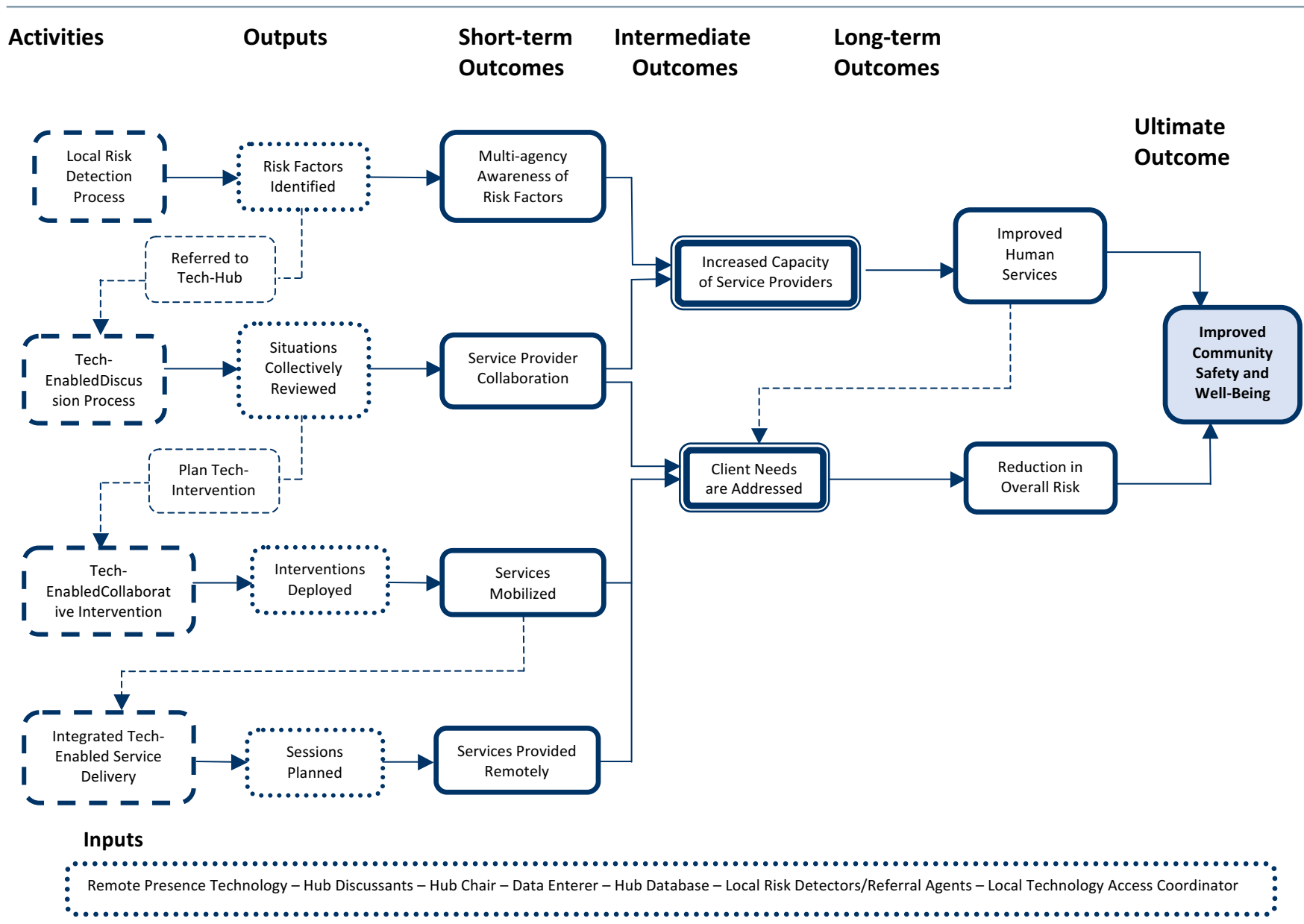

FIGURE 1 An illustration of a conceptual understanding of the linkages between outputs and outcomes to be generated by the Tech-Enabled Hub.

Table III illustrates, there are three different configurations under which a tech-enabled Hub could operate.

As Table III describes, each of the team configurations presents its own strengths and weaknesses. In many ways, there is a trade-off for one configuration over another. For example, in the regional or provincial configuration, there is a greater opportunity for at least one member of the team to accompany local human service professionals on the initial intervention (while the others join remotely). Unfortunately, this does not allow the team very much face-to-face time with one another. In contrast, the single location tech-enabled Hub provides an opportunity for Hub discussants to build rich, strong personal working relationships. This, of course, comes at the expense of opportunities for at least one member of the team to attend the actual intervention door knock with local service providers (and/or the technology access coordinator). To illustrate the reach of a potential tech-enabled Hub, Figure 2 maps a provincial configuration applied in Saskatchewan.

\section{Appropriate ICT Solutions}

Beyond the configuration of the tech-enabled Hub, a number of suggestions for a technological format have also been offered. Many of the consultation respondents converged around the notion that the ICT solution can differ depending upon the stage of collaborative risk-driven intervention. As Table IV illustrates, actual Hub meetings would be suitable in stationary video conferencing environments like Telehealth, GoTo, or Skype. Actual interventions, however, must be done using mobile telepresence technologies on a satellite or $4 \mathrm{G} / \mathrm{LTE}$ Internet platform. The actual postintervention service provisions could be done using a variety of formats-depending upon client comfort, interest, and capacity.

\section{Feedback from Stakeholders}

During development of the pilot project plan, a second wave of feedback was requested from 27 key stakeholders involved in the Hub Model. This follow-up cohort included $8 \mathrm{Hub}$ chairs from across Saskatchewan; 1 Hub Chair from Ontario; 3 representatives of RCMP " $F$ " Division; 2 Hub data analysts; 4 Ministry of Justice representatives; 4 key advisors on collaborative risk-driven intervention; 2 Hub supporters; and 3 Hub evaluators. The purpose of this follow-up was to present some basic principles of the emerging pilot project and seek observations and feedback. This feedback was used to finetune, adjust, and focus the final project plan presented herein.

Overall, the feedback from the follow-up stakeholder group was quite positive. Most of the respondents were very supportive of the direction of the pilot project plan 
TABLE II A listing of the risks and strategies for overcoming risks associated with a tech-enabled Hub

\begin{tabular}{|c|c|}
\hline Risks & Strategies for Overcoming Risk \\
\hline Inadequate access to appropriate technology. & $\begin{array}{l}\text { Confirm key components of ICT in communities that will be part of the } \\
\text { pilot project. }\end{array}$ \\
\hline Lack of community buy-in. & Spend time working with community leaders to build buy-in and support. \\
\hline Low levels of risk detection at the local level. & $\begin{array}{l}\text { Educate and raise local awareness of the utility found in early risk } \\
\text { detection and intervention. }\end{array}$ \\
\hline Failure to secure full-time Hub discussants. & $\begin{array}{l}\text { Work with multiple levels of government and service organizations to } \\
\text { secure a proper commitment. }\end{array}$ \\
\hline Low client comfort level with technology. & $\begin{array}{l}\text { Assist clients in exploring the user-friendliness of the technology with } \\
\text { onsite support. }\end{array}$ \\
\hline $\begin{array}{l}\text { Hub discussants will not be able to create team synergy in a } \\
\text { tech-enabled environment. }\end{array}$ & $\begin{array}{l}\text { Provide opportunities for daily interaction and exchange among the } \\
\text { Hub discussants. }\end{array}$ \\
\hline $\begin{array}{l}\text { Some agencies may not be able to participate in a } \\
\text { tech-enabled environment. }\end{array}$ & $\begin{array}{l}\text { Work with agency leaders and funding organizations to open up } \\
\text { opportunities for full participation. }\end{array}$ \\
\hline $\begin{array}{l}\text { Conflict and confusion over jurisdictional authority and } \\
\text { responsibility of service provision. }\end{array}$ & $\begin{array}{l}\text { Hold planning sessions early on with the appropriate service providers } \\
\text { to sort out jurisdictional questions and potential problems. }\end{array}$ \\
\hline $\begin{array}{l}\text { Geographic and resource barriers to ICT specialists who can } \\
\text { service, troubleshoot, and repair ICT solutions onsite. }\end{array}$ & $\begin{array}{l}\text { Identify local or regional ICT resources who can work remotely with } \\
\text { central ICT vendor to implement immediate solutions. }\end{array}$ \\
\hline
\end{tabular}

TABLE III Three types of configurations for implementing a tech-enabled Hub

\begin{tabular}{|c|c|}
\hline Configuration & Description \\
\hline $\begin{array}{l}\text { Single Location } \\
\text { Tech-Enabled Hub }\end{array}$ & $\begin{array}{l}\text { The Hub team may be comprised of human service providers located in a single community, where they can work } \\
\text { together in-person, but serve clients remotely. The benefit of this is strong team synergy. The challenge with this is } \\
\text { lack of client contact and a threat of low risk detection. Depending on the number of new discussions, this design } \\
\text { may require full-time resources to the Hub table. }\end{array}$ \\
\hline $\begin{array}{l}\text { Regional } \\
\text { Tech-Enabled Hub }\end{array}$ & $\begin{array}{l}\text { The Hub team is comprised of human service providers from different locations within a specific region of the } \\
\text { province. Each Hub discussant may play the lead role in interventions within their service area, while also being } \\
\text { supported remotely by the remaining Hub discussants. This design may allow for home agency responsibilities as } \\
\text { well as Hub duties. }\end{array}$ \\
\hline $\begin{array}{l}\text { Provincial } \\
\text { Tech-Enabled Hub }\end{array}$ & $\begin{array}{l}\text { The Hub team is comprised of human service providers from different locations throughout the province. Each Hub } \\
\text { discussant may play the lead role in interventions within their service area, while also being supported remotely } \\
\text { by the remaining Hub discussants. Depending on the number of new discussions, this design may require full-time } \\
\text { resources to the Hub table. }\end{array}$ \\
\hline
\end{tabular}

and offered only encouraging words. Others, while very supportive, did offer some helpful constructive points for consideration.

The main theme of the feedback was to "get the technology right." In other words, they felt that there was not a lot to change with respect to the actual Hub Model itself. However, the solution chosen to connect Hub practitioners and clients remotely must be perfect. Another theme in the feedback was that there must be a commitment among human service providers to support clients beyond the initial door knock. In a conventional Hub Model application, many Hub discussants connect/refer Hub subjects to other service providers. According to several respondents, that may not be an ideal configuration for this model-as the use of technology is a big enough barrier to rapport, let alone have two or three different service providers from the same agency. The third major theme was that members of the so-called tech-enabled Hub team must be completely comfortable with working in a technological environment. Furthermore, they must be particularly effective at overcoming the human element lost in a technological environment.
In addition to these main themes, the follow-up stakeholder group offered a few additional suggestions and observations:

The technology used must offer a reliable, clear, and secure connection.

- The Four Filter process will be able to endure a tech application. Door knocks are individualized anyway, so nothing much should change on the intervention front.

- A regional approach offers a balance of local onsite human service providers with remote professionals.

- There is real merit to incorporating technology not only in the discussion process, but also for both the interventions and ongoing service supports.

- This approach will offer considerable accessibility to services-which continues to be a major burden, even in larger urban environments.

- The concept is a major win for remote locations that face geographic barriers. However, it could easily become an opt-out of face-to-face service provision in urban environments. 
In structuring the service areas, it is important to pay attention to jurisdiction, overlap, and even service competition.

- The key to this will be a mechanism of early risk detection and referral from local human service professionals or community members who are not all that familiar with the Hub Model.

- The only way this approach becomes worthwhile is if service provision is guaranteed after the interventioneven it is done remotely.

- It will be critical to have at least one person on the ground to coordinate access to the technology solution that this approach requires.

\section{Resource Requirements}

In preparing to implement this pilot project, it will be important to budget for a number of key resources. These resources are the basic requirements for launching a tech-enabled Hub. As the implementation team begins their work, they may find

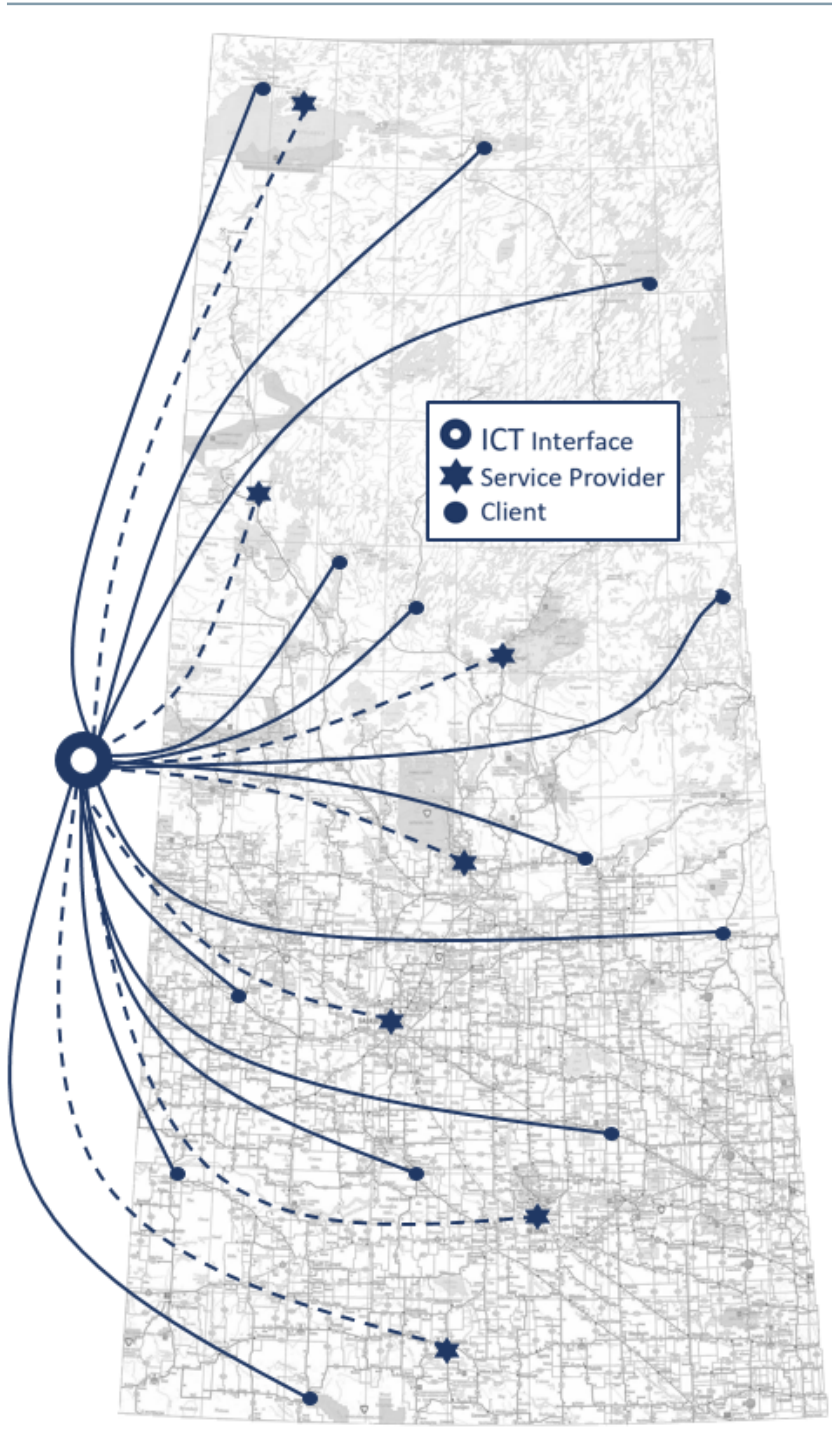

FIGURE 2 How a provincially-configured tech-enabled Hub could be applied in the province of Saskatchewan. additional resources that are needed. For now, however, some of the major resource requirements for a tech-enabled Hub are described in Table V.

TABLE IV The appropriate technology format for each stage of the collaborative risk-driven intervention process

\begin{tabular}{|c|c|}
\hline Stage & Format(s) \\
\hline $\begin{array}{l}\text { Hub Discussion } \\
\text { Process }\end{array}$ & $\begin{array}{l}\text { Stationary web-based video } \\
\text { conferencing (e.g., Skype, GoTo, } \\
\text { WebEx, or various Wi-Fi telepresence } \\
\text { devices) }\end{array}$ \\
\hline $\begin{array}{l}\text { Intervention } \\
\text { Planning }\end{array}$ & $\begin{array}{l}\text { Stationary web-based video } \\
\text { conferencing (e.g., Skype, GoTo, } \\
\text { WebEx, or various Wi-Fi telepresence } \\
\text { devices) }\end{array}$ \\
\hline $\begin{array}{l}\text { Intervention } \\
\text { Deployment }\end{array}$ & $\begin{array}{l}\text { Remote presence technology/mobile } \\
\text { video solutions (e.g., satellite video } \\
\text { conferencing, mobile telepresence } \\
\text { device; } 4 G / \text { LTE tablet) }\end{array}$ \\
\hline $\begin{array}{l}\text { Post-Intervention } \\
\text { Service Provision }\end{array}$ & $\begin{array}{l}\text { Combination of stationary web-based } \\
\text { videoconferencing (e.g., Skype, } \\
\text { GoTo, WebEx), mobile video solutions } \\
\text { (e.g., satellite video conferencing, } \\
\text { mobile telepresence device, } 4 \mathrm{G} / \mathrm{LTE} \\
\text { tablet), or text-based communication } \\
\text { (e.g., cell phone) }\end{array}$ \\
\hline
\end{tabular}

TABLE V The required resources of a tech-enabled Hub by resource type

\begin{tabular}{ll}
\hline Resource Type & \multicolumn{1}{c}{ Description } \\
\hline Personnel & Hub discussants from multiple sectors \\
& who are comfortable and committed to \\
& collaboration and ongoing service provision \\
& in a technological environment. \\
- & Hub chairperson who can steer the meetings \\
& (e.g., 2 discussants serving as co-chairs). \\
- & Data recorder (could be a Hub discussant, \\
& as well). \\
- & Onsite technology access coordinator. \\
- & Diverse ICT solution that allows multi-site \\
& stationary video communication. \\
- & Reliable ICT solution that allows multi-site \\
& mobile video communication. \\
- & Access to sufficient $4 G$, LTE, or satellite \\
& networks. \\
Technology & Individual devices (e.g., desktop, tablet) \\
& exclusive to Hub discussants. \\
- & Training for Hub discussants on effective \\
& communication in a technological \\
& environment. \\
- & Local human service provider awareness on \\
& risk detection and referring to Hub. \\
- & Training for technology access coordinator \\
& to become familiar with the Hub Model, as \\
& well as leading practices in supporting client \\
& engagement in services. \\
\hline Training \& &
\end{tabular}




\section{Cost Simulation}

The main reason for developing this pilot project is to identify an opportunity for individuals in rural/remote communities to overcome the geographic and resource barriers to collaborative risk-driven intervention (and other service provisions). The fact of the matter is, some

TABLE VI The costs of different human service solutions for supporting a client $200 \mathrm{~km}$ away from any given service provider

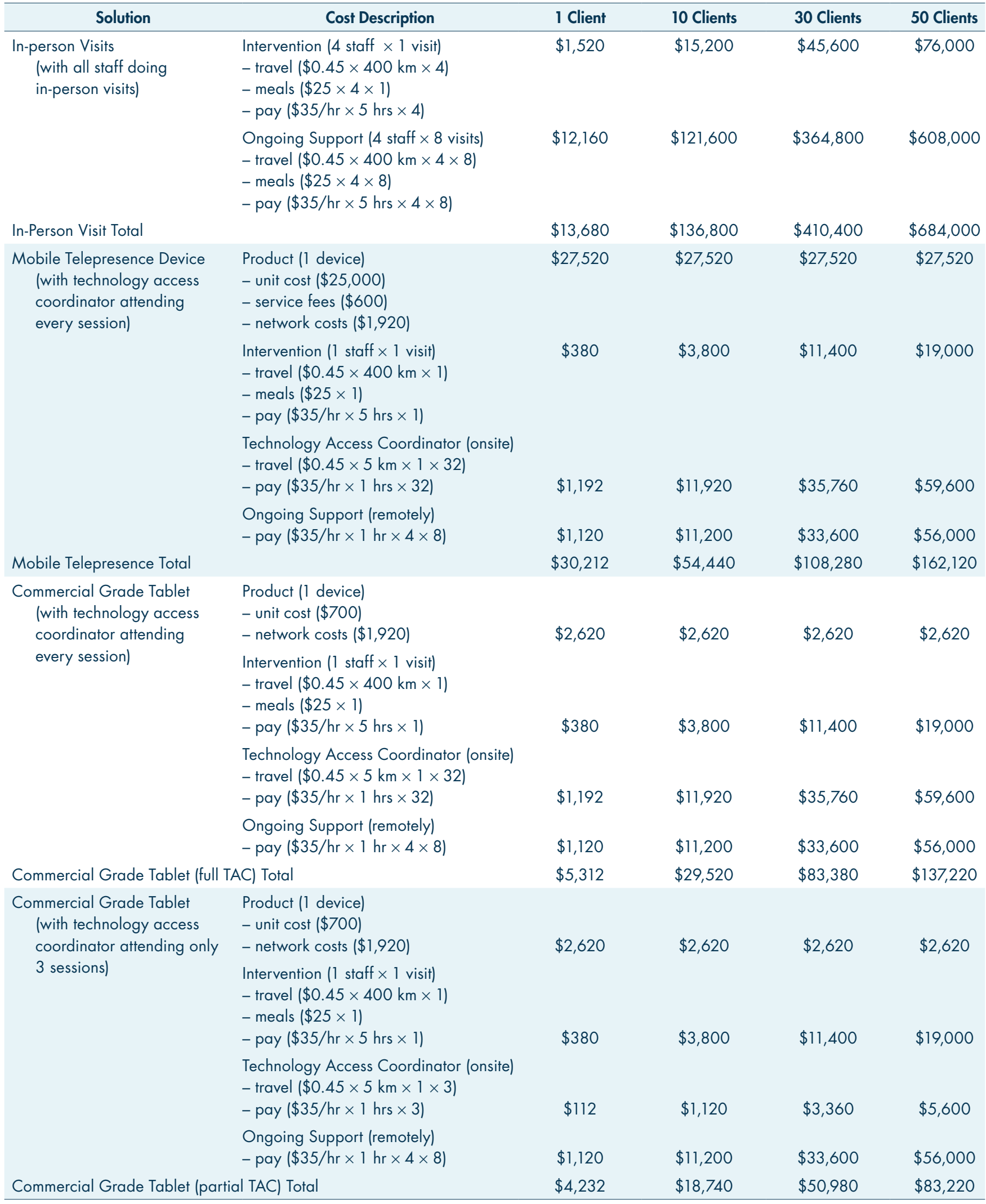


communities simply do not and will not have onsite access to all required services. Considering this, four scenarios are presented.

The first involves all onsite support to the client. The second involves a local technology access coordinator taking an industry-grade mobile telepresence device to the client's home for each session. The third involves a local technology access coordinator taking a commercial grade tablet to the client's home for each session. Finally, the fourth involves a local technology access coordinator limiting their visits with the client to three-only to support them in using the tablet (which will be left with the client).

This cost simulation assumes that any single client who faces a situation of acutely-elevated risk will require a single intervention involving four sectors. During the onsite intervention, all four relevant Hub discussants will attend the intervention in-person, whereas in the tech-enabled interventions, only one Hub discussant will attend the intervention in-person (the rest online). Following the intervention, the client will require multiple services by four different professionals, in eight sessions, over a one-year period. The client is located $200 \mathrm{~km}$ from the nearest service delivery centre. In the tech-enabled models, a technology access coordinator from the local community will bring the device to the client for tech-enabled sessions. In the onsite model, the four human service professionals will each visit the client at the client's home (200 km away).

As Table VI shows, there are some tremendous cost differences between onsite support and tech-enabled support. In fact, all three tech-enabled solutions are considerably more cost-effective than complete onsite service provision. Among the tech-enabled solutions, the difference in costs decreases with higher volumes of clients served. In other words, there is a base rate to acquire the technology, but after that, costs for implementing each solution are relatively similar.

\section{CONCLUSIONS}

The research and consultations conducted in preparation of a tech-enabled Hub pilot project inform scholars and practitioners of a few things. The first is that there is an appetite and interest in utilizing technology to overcome barriers to human service delivery in rural and remote communities. The second is that the fidelity and strength of collaborative risk-driven intervention, while largely a faceto-face model, should be able to withstand application in a virtual environment. The third is that, out of necessity, parties to this would-be tech-enabled Hub have an un-scripted opportunity to explore ongoing multi-sector coordinated support beyond the point of intervention. This third point in particular, has the potential to open up an entirely new field of practice in multi-sector collaborative community safety and well-being.

One opportunity realized through this project is that the delivery of human services through a virtual environment can extend far beyond the Hub Model. In fact, it could be argued that many barriers to human service delivery (e.g., transportation, anonymity, stigma, comfort) can be just as easily overcome by deploying the right technology in a small or large urban community as in a rural or remote community. With transitions to an ICT platform for banking, medical diagnostics, post-secondary education, and ordering pizza already behind us, there is little reason to doubt the potential for virtual applications of broader human service delivery.

Concerning the role of academia in this emerging field, there are endless opportunities for action-based research to shape, measure, improve, and sustain the application of collaborative risk-driven intervention in a virtual environment. Getting to a place of consistent and effective tech-enabled human service delivery will certainly require systematic reflection, monitoring, and evaluative reporting. Hopefully this article will inspire community-engaged scholars to mobilize and meet such needs.

Moving forward, Community Safety Knowledge Alliance and its various academic and government partners are pursuing funding opportunities to implement a pilot project. While much work will be required to initiate the pilot, a lot has been learned about the Hub Model, human service delivery in general, and how both can be enhanced through information and communication technology. Beyond just collaborative risk-driven intervention, there is an incredible opportunity for academics, practitioners, and government to further explore this emerging nexus of upstream human service delivery and technology.

\section{ACKNOWLEDGMENTS}

This research project was conducted by the University of Saskatchewan's Centre for Forensic Behavioural Science and Justice Studies at the request and coordination of Community Safety Knowledge Alliance. Funding for this project was provided by the Canadian Safety and Security Program, a federal program led by Defense Research and Development Canada's Centre for Security Science, in partnership with Public Safety Canada. The accountable partner in this project was RCMP "F" Division.

\section{CONFLICT OF INTEREST DISCLOSURES}

The author of this article holds a business relationship with the Editor-in-Chief of this Journal. This paper represents a modified series of extracts from an original document released by Community Safety Knowledge Alliance (available at: http://www.cskacanada. ca/news/81-technology-enabled-hubs-in-remote-communitiesfinal-report-released). See also Nilson (2017). Collaborative risk-driven intervention: technology-enabled opportunities in rural and remote communities (A Pilot Project Plan) Saskatoon, SK: Centre for Forensic Behavioural Science and Justice Studies-University of Saskatchewan/ Community Safety Knowledge Alliance.

\section{AUTHOR AFFILIATIONS}

${ }^{*}$ Centre for Forensic Behavioural Science and Justice Studies, University of Saskatchewan, Saskatoon, SK, Canada.

\section{REFERENCES}

Akomea-Bonsu, C. (2012). The impact of information and communication technologies on small and medium scale interprises (SMEs) in the Kumasi Metropolis, Ghana, West Africa. European Journal of Business Management, 4(20), 152-158.

Avgerou, C. (2003). The Link Between ICT and Economic Growth in the Discourse of Development. In M. Korpela, R. Montealegre, \& A. Poulymenakou (eds), Organizational Information Systems in the Context of Globalization. IFIP - The International Federation for Information Processing, vol 126. Boston, MA: Springer,

Babayan, A., Landry-Thompson, T., and Stevens, A. (2015). Evaluation of the Brant Community Response Team Initiative: Six-month report. Brantford ON: Brant County Health Unit. 
Brown, J., and Newberry, J. (2015). An evaluation of the connectivity situation tables in Waterloo Region. Evaluation report submitted to Waterloo Region Connectivity Partnership. Guelph, ON: Taylor Newberry Consulting

Caperna, A. (2010). Integrating ICT into sustainable local policies. In Silva, C. (ed.), Handbook of research on E-Planning: ICTs for urban development and monitoring, pp.340-364. Hershey, PA: Information Science Reference.

Cohen, D., Garibaldi, P., and Scarpetta, S. (eds.) (2004). The ICT revolution: Productivity, differences and the digital divide. Oxford, UK: University of Oxford Press.

Del Grosso, P., Kleinman, R., Mraz Esposito, A., Sama Martin, E., \& Paulsell, D. (2014). Assessing the evidence of effectiveness of home visiting program models implemented in tribal communities. Washington, DC: U.S. Department of Health and Human Services.

Dimitrios, B., and $\mathrm{O}^{\prime}$ Connor, P. (2005). Information communication technology: Revolutionizing tourism. Tourism Recreation Research, 30(5), 7-16.

Global Network for Community Safety. (2016). $1^{\text {st }}$ Canada-Wide Account of Hub/Situation Table Adopter Sites and Situations Triaged for Acutely Elevated Risk - Since 2011. Toronto, ON: The Network. Retrieved from www.globalcommunitysafety.com

Gray, S. (2016) Lanark County Situation Table Project: Annual Report September 2015 - September 2016. Perth, ON: Lanark County Situation Table.

Keewatin Yatthé Regional Health Authority (KYRHA). (2015). The strength of our family: A home-based, family-centred, multi-sector program for helping children and families exposed to violence - facilitation manual. Buffalo Narrows, SK: Keewatin Yatthé Regional Health Authority.

Kozma, R. (2005). National policies that connect ICT-based education reform to economic and social development. Human Technology, 1(2), 117-156.

Lansdowne Consulting. (2016). Multiagency Early Risk Intervention Tables (MERIT): Pilot project review. Ottawa, ON: The Lansdowne Consulting Group.

Litchmore, R. (2014). Preliminary report on the progress of the Guelph Situation Table. Internal Report Provided to Guelph Situation Table. Guelph, ON: University of Guelph.

McFee, D., and Taylor, N. (2014). The Prince Albert Hub and the Emergence of Collaborative Risk-Driven Community Safety. In Murphy, C. (ed). Change and innovation in Canadian policing. Canadian Police College Discussion Paper Series. Ottawa, ON: Canadian Police College.

Naylor, P., McKay, H., Scott, J., Bridgewater, L., Drummond, J., \& Panagiotopoulos, C. (2009). Exploring the implementation and potential adaptation of action schools! BC for Rural and Remote First Nations Communities. Vancouver, BC: Canadian Council on Learning.

Newberry, J., and Brown, J. (2017). An evaluation of the Connectivity Situation Tables in Waterloo Region: Service user experiences and impact on use of emergency services. Evaluation report submitted to Waterloo Region Connectivity Partnership. Guelph, ON: Taylor Newberry Consulting.

$\mathrm{Ng}$, S., and Nerad, S. (2015). Evaluation of the FOCUS Rexdale pilot project. Delivered to the City of Toronto and Toronto Police Service. Toronto, ON: Vision and Results Inc. and SN Management.
Nilson, C. (2014). Risk-Driven collaborative intervention: A preliminary impact assessment of community mobilization Prince Albert's Hub Model. Saskatoon, SK: Centre for Forensic Behavioural Science and Justice Studies/University of Saskatchewan.

Nilson, C. (2016a). Collaborative risk-driven intervention: A study of Samson Cree Nation's application of the Hub Model. Ottawa, ON: Public Safety Canada.

Nilson, C. (2016b). Chatham-Kent's fast intervention risk specific teams: Final evaluation report. Toronto, ON: Global Network for Community Safety.

Nilson, C. (2017). Collaborative risk-driven intervention evaluation brief: A preliminary analysis of discussion subject, table discussant, and key stakeholder satisfaction, understanding, and perceived impact of Collaborate Barrie. Toronto, ON: Global Network for Community Safety.

Pelgrum, W. (2001). Obstacles to the integration of ICT in Education: Results from a worldwide educational assessment. Computers \& Education, $37(2), 163-178$

Rouse, M. (2005). ICT linformation and communications technology or technologies) [blog post]. Retrieved from http://searchcio.techtarget.com/definition/ ICT-information-and-communications-technology-or-technologies

Russell, H., and Taylor, N. (2014). New directions in community safety: Consolidating lessons learned about risk and collaboration. An Interpretive Guide to Information Sharing Practices in Ontario...Within the Context of Collaborative, Risk-driven Community Safety and Wellbeing. Ontario Working Group on Collaborative Risk-Driven Community Safery. Toronto, ON: OACP.

Selwin, N., Gorad, S., and Furlong, J. (2006). Adult learning in the digital age: Information technology and the learning society. Abingdon, UK: Routledge, Taylor and Francis Group.

Silva, C. (ed.), (2010). Preface. In Silva, C. (ed.), Handbook of research on E-Planning: ICTs for urban development and monitoring, pp.xx-xxiv. Hershey, PA: Information Science Reference.

Skubby, D., Bonfine, N., Novisky, M., Munetz, M. R., \& Ritter, C. (2013). Crisis Intervention Team (CIT) programs in rural communities: A focus group study. Community Mental Health Journal, 49(6), 756-764.

TechTerms (online dictionary). (2010). ICT definition. Retrieved from https:// techterms.com/definition/ict

Trucano, M. (2005). Knowledge maps: ICT in education. Washington, DC: infoDev/World Bank.

Waegemakers-Schiff, J., and Turner, A. (2014). Housing first in rural Canada: Rural homelessness and housing first feasibility across 22 Canadian communities. Calgary, AB: University of Calgary.

Wang, F., Carley, K., Zeng, D, \& Mao, W. (2007). Social computing: From social informatics to social intelligence. IEEE Intelligence Systems, 22(2). 79-83.

Zuppo, C. (2012). Defining ICT in a boundaryless world: The development of a working hierarchy. International Journal of Managing Information Technology (IIMIT), 4(3), 13-22. 